\title{
UNDERSTANDING HOW ORGANIZATIONAL CULTURE TYPOLOGY RELATES TO ORGANIZATIONAL UNLEARNING AND INNOVATION CAPABILITIES
}

\begin{abstract}
This study focuses on the link between organizational unlearning and innovation capabilities and explores how this relationship might be managed within an innovative firm. In order to gain a clearer insight into to the influence of a firm's culture on organizational unlearning and its innovation capabilities, a research model was developed that employs the Competing Values Framework (Cameron \& Quinn, 1999). In this model, the influence of a firm's cultural typology on unlearning and innovation is conceptualized and hypotheses are developed. The model was tested empirically using a sample of 145 firms drawn from the Spanish automotive components manufacturing sector and the relationships between the constructs were assessed using the partial least squares path-modeling approach. The results reveal that each distinct organizational culture exerts a different impact on the innovation and unlearning outcome variables. In particular, an adhocracy culture is associated closely with innovation capabilities while a market culture exerts a significant influence on organizational unlearning.
\end{abstract}

Keywords: organizational culture, cultural typologies, unlearning, innovation, partial least squares.

\section{Introduction.}

Within a knowledge-based economy, firms use knowledge as strategic input resource in the creation of knowledge-intensive products and services (Seddighi, 2015). In this environment, organizations must be prepared to adapt to the high levels of turbulence and uncertainty that can be experienced. Faced with these challenges, knowledge can easily become obsolete and firms have to face this complexity by constantly renewing their knowledge bases. Organizational learning has an important role in that renewal (Sanz-Valle et al., 2011). At the same time, innovation capability enables organizations to become more proficient in both exploiting opportunities and seeking new challenges (Matzler et al., 2013). Innovation allows firms to be more flexible in their structures, and as a consequence innovative firms find it easier to adapt to a rapidly changing business environment. This adaptation enables firms to handle and leverage opportunities better than their competitors (Damanpour \& Gopalakrishnan, 2001) and is a source of sustainable competitive advantage.

According to Senge (1990), fostering organizational learning mechanisms - the capacity to learn faster than competitors - is perhaps the only way of paving the way for innovation in firms, and hence, achieving this sustainable competitive advantage. Furthermore, Akgün et al. (2007) observe that organizational unlearning by itself is insufficient for the development and fostering of organizational knowledge and insight. They argue that, in order to be able to renew their knowledge bases, firms ought also design, encourage and support a process of organizational unlearning. 
Research with the aim of discovering the main drivers of learning processes and innovation at the firm level has been extensive. Several empirical studies have considered organizational culture as one of the main drivers of knowledge management, organizational learning mechanisms and firm innovativeness and have addressed these relationships (De Long and Fahey, 2000; Argote et al., 2003; Sanz-Valle et al., 2011). However, relatively little attention has been paid to the links between organizational culture, organizational unlearning and innovation capability. There is, especially, little empirical evidence as to what extent organizational culture relates to unlearning and innovation. Therefore, the purpose of our study is to explore the links among the different organizational culture typologies with organizational unlearning and innovation using the competing values framework proposed by Cameron and Quinn (1999).

Our paper first presents the theoretical background and the development of our research model and hypotheses. Then the research method that we adopted to test our hypotheses is described. This is followed by a presentation of our data analysis and our findings. We then discuss the contribution of our findings and the implications and limitations of our research are highlighted along with suggested directions for future research in this area.

\section{Theoretical Background.}

\subsection{Linking organizational culture typologies with unlearning and innovation.}

Organizational unlearning (OU) can be broadly defined as the process by which firms remove old logics and behaviors and make room for new ones (Cegarra-Navarro,; Eldridge and Gamo, 2012). Prior studies conceptualize OU as "the process of reducing or eliminating pre-existing knowledge or habits" (Akgün et al., 2002, p.60), or "the process by which individuals and organizations acknowledge and release prior learning in order to accommodate new information and behaviors” (Becker, 2005, p.661). We approach OU from the perspective proposed by Cegarra and Sánchez (2008), which considers OU as a multidimensional construct shaped by three dimensions: (1) the examination of lens fitting; (2) the framework for changing individual habits; and (3) the framework for consolidating emergent understandings.

The link between organizational learning (OL) and innovation capability has been assessed in a prior study (García-Morales et al., 2006) which concludes that OL is a critical part of innovation. OU is itself an integral part of the OL process and becomes a key factor in the development of innovations. In this vein, Becker (2008) suggests that the principal purpose of fostering and committing to $\mathrm{OU}$ is that it enables the acquisition of new information and behaviors, as well as being a mechanism that drives change and innovation. This particular link (OU-innovation) gives rise to the third hypothesis of our model and will be discussed further in a later sub-section.

Büschgens et al. (2013) suggest that organizational culture (OC) is a key to innovation success. There is strong evidence related to the positive relationship between OC and firm innovativeness (Deshpande et al., 1993; Hernández-Mogollón et al., 2010). A firm that really intends to be innovative must have an OC that strongly allows and supports innovation (Santos-Vijande and Alvarez-Gonzalez, 2007). Firms that are renowned for 
their ability to create and commercialize new technologies frequently emphasize their unique cultures and there are some good examples of how distinctive organizational cultures have driven successful innovations (e.g. Apple; Samsung; 3M). In this sense, different styles of OC will directly influence OL and organizational innovation (Liao et al., 2012) but further research is needed concerning the link between OC and OU.

In our study, OC was approached from the perspective of the Competing Values Framework (CVF) model (Cameron and Quinn, 1999). This model comprises two dimensions with the first dimension relating to formal and informal processes and the second relating to strategic focus. Formal processes are characterized by high degrees of stability, order and control, whereas informal processes involve a greater degree of flexibility and laxity. The CVF perspective suggests that a firm with a flexible organizational culture will be more innovation-oriented than a firm with a stable culture. Hence, flexibility behaves as a facilitating agent of innovation while stability is believed to act as a barrier to innovation (Jaskyte, 2004). The strategic focus dimension contrasts internal integration with external adaptation and differentiation. From this perspective, Desphande et al. (1993) argue that internally-oriented cultures may provoke a lack of attention to the market changes which constitute an essential issue in innovation processes. An organization with an externally-oriented culture will find it easier to obtain key external information which may be helpful to develop and sustain an innovative capability.

These two dimensions are mapped against each other in the CVF to identify four different types of organizational culture: adhocracy culture, hierarchy culture, clan culture and market culture as shown in Figure 1. Each of these cultural typologies involves particular and distinctive characteristics that make them more or less conducive to OU mechanisms and innovation within firms.

Figure 1. The Competing Values Framework

Flexibility and discretion

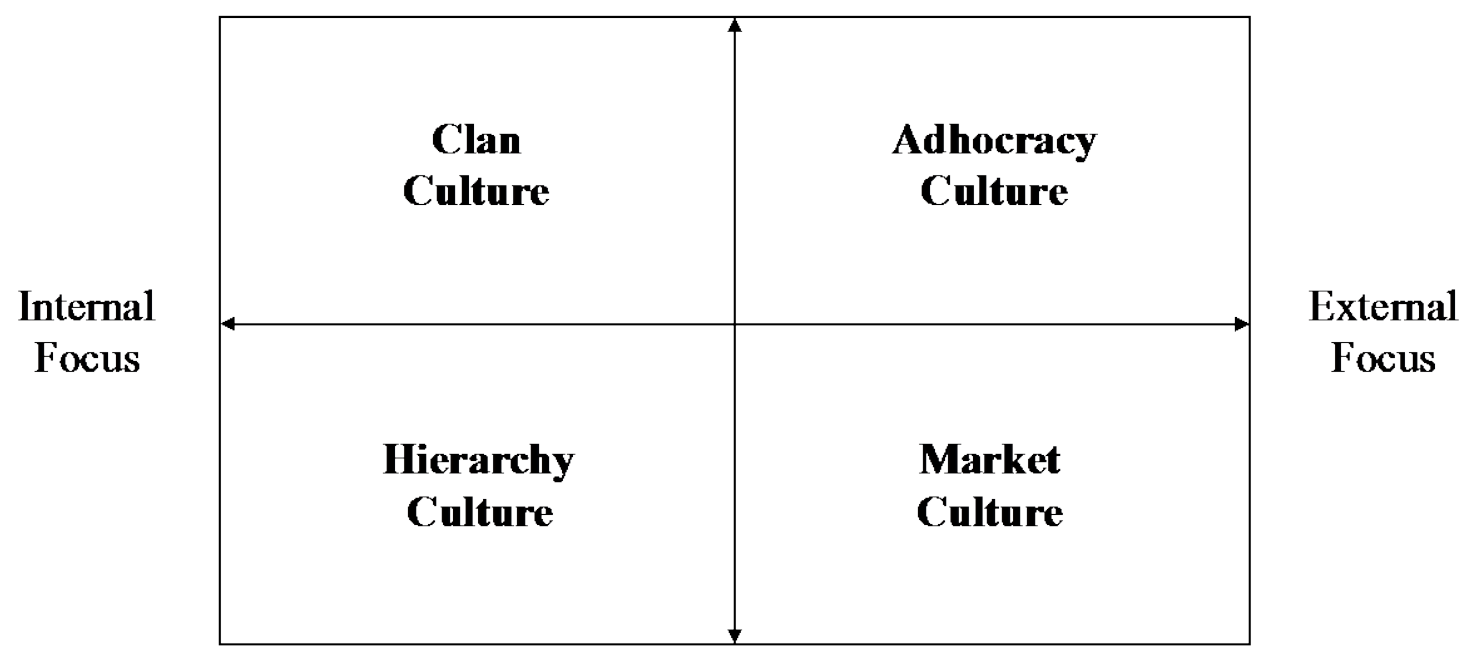

Stability and control

Adhocracy culture is often labeled as creative, dynamic, entrepreneurial, innovative, ready for change, aggressive and adaptable. Organizations possessing this type of OC 
seek efficiency while focusing on innovation, growth and new resources (Desphande et al., 1993). Therefore, this is the most innovation-oriented cultural typology. Prior studies have revealed that, in order to achieve this goal, an adhocracy culture is based on values such as risk tolerance (Tellis et al., 2009; Cooper et al., 2004) and commitment to learning (McLaughlin, 2002). Thus, firms with an adhocracy culture are able to respond quicker to changes in their environment and are ready to assume higher risks.

Hierarchy culture is often described as bureaucratic, rule-bound, by-the-book, and topdown (Zammuto et al., 2000). This type of OC is sustained by very small ambiguity levels and by an excessive sense of safety, predictability, efficiency, stability, and uniformity. Early studies, such as those of Burns and Stalker (1961) and Bennis (1966) suggest that bureaucracy is an ineffective organizational form when attempting to deal with the complexity of the environment and the need for change. Other studies have indicated that bureaucracy works properly in the development of innovations but is unable to generate them (Pierce and Delbecq, 1977). This cultural typology maintains a permanent concern for order and control embodied in rules, instructions or very strict procedures. These can impede experimentation, change and creativity which are essential for the development of innovation. Furthermore, this cultural typology has an internal focus which is more oriented to retaining the rigid hierarchical structure rather than seeking innovative business opportunities in the market.

Clan culture is often referred as family, trust, loyalty, empowerment and collegiality (Cameron and Quinn, 1999). Other critical elements are flexibility and decentralization which imply both greater participation and self-control. This is a cultural typology which primarily focuses on human resources and morale to the extent that its key values system is expressed in terms of the organization's concern for its employees and emphasizes positive working relationships. Organizational cohesiveness and personal satisfaction account more than financial and market objectives (Keskin et al., 2005). The firm's commitment to humane treatment and development fits well with the innovative philosophy as it may enable cooperation and contribute to generate shared knowledge (Boothby et al., 2010). However, the strong emphasis on people issues might be a handicap for the implementation of new developments. For example, if priority is given to the interests of individuals or groups, this might impede innovation implementation (Büschgens et al., 2013). Thus, the emphasis on flexibility would support and enable innovation but the internal strategic approach that characterizes this type of culture may hinder it.

In common with clan culture, market culture also presents a hybrid situation. While a dimension drives innovation (commitment to the market needs and changes, for example through the orientation towards competitiveness and differentiation), the other hinders it (the desire for control). This cultural typology is known as the rational goal model with productivity, efficiency, competitiveness, and results-orientation being its prevailing values. Market culture emphasizes gaining reputation and success and the strong competitiveness that characterizes it could lead to the development of innovations because striving for efficiency requires continuous improvement. However, the second dimension of a market culture is oriented towards control rather than flexibility. Planning, managing by objectives and measuring deviations comprise formal control mechanisms involving compliance with certain rules and standards. This can constrain the creativity that is required for the development of new innovations. 
OL is a dynamic cycle in which knowledge absorption mechanisms follow the processes of knowledge forgetting. This leads us to consider the impact of OC on OU while recognizing that $\mathrm{OU}$ is a stage of the OL process. In this vein, De Long and Fahey (2000) identify four manners in which organizational culture impacts on OL. The first manner considers that culture shapes employees' assumptions about whether knowledge remains important and which knowledge becomes useless and should be abandoned. A second manner states that culture permits the integration of individual knowledge into the firm's knowledge base. Another manner states that new knowledge is created, legitimized and distributed on the basis of the cultural typology inherent in the firm. Finally, culture enables a context for social interaction that ultimately defines how effective a firm can be at creating, sharing and applying knowledge. Firms with adhocracy or clan culture favor this knowledge transfer and dissemination whereas firms with a more control-oriented and bureaucratic culture (hierarchy and market typologies) may provide a barrier to this. Consequently, different organizational cultures will have different influences on OL and OU.

In view of the prior discussions, it can be assumed that cultural typologies that foster creativity, dynamism, competitiveness, differentiation and are strategically oriented to predict and satisfy market changes will favor or enable innovation and OU. Alternatively, it may be expected that cultural typologies that emphasize formal processes based upon control, order, bureaucracy and stability may hinder firm innovativeness and OU. Consequently, adhocracy and market cultures are expected to have a positive impact on the firm's innovativeness and OU though market culture is expected to have less effect than adhocracy. Furthermore, the combination of the internal focus with a greater emphasis on formal and regulated processes causes the inability of firms with a hierarchical culture to unlearn or innovate and thus presents the lowest levels of innovation and OU. Finally, despite the fact that clan culture is defined by a high level of flexibility, which could act as enabler of unlearning and innovation, its lack of external orientation makes it unlikely to foster both OU or the design and development of innovations. Therefore, our study proposes the following hypotheses which are illustrated in Figure 2:

H1: Organizational culture will affect firm innovativeness. In particular:

H1a: Clan culture is negatively linked to firm innovativeness.

H1b: Adhocracy culture is positively linked to firm innovativeness.

H1c: Market culture is positively linked to firm innovativeness.

H1d: Hierarchy culture is negatively linked to firm innovativeness.

H2: Organizational culture will affect organizational unlearning. In particular:

H2a: Clan culture is negatively linked to organizational unlearning.

H2b: Adhocracy culture is positively linked to organizational unlearning.

H2c: Market culture is positively linked to organizational unlearning.

H2d: Hierarchy culture is negatively linked to organizational unlearning.

2.2. Linking organizational unlearning with innovation outcomes. 
Damanpour (1991) understands innovation as the firm's ability to effectively generate and develop new products, services or processes. Fiol (1996) suggests that a firm's potential to generate innovation outcomes depends on the prior gathering and absorption of knowledge. Furthermore, the emergence of knowledge management as an academic discipline strengthens the reciprocity between innovation and knowledge in the sense that a firm's investment in knowledge and knowledge workers will result in improved innovation outcomes. Similarly, the firm's involvement within innovation processes may also contribute to building new knowledge (Prajogo \& Ahmed, 2006).

Some studies suggest that the ability to effectively exploit external knowledge constitutes a critical factor for companies interested in developing as innovative firms (Cohen \& Levinthal, 1990). The firm's absorptive capacity enables turning knowledge into new products, services, or processes to support innovation (Cepeda-Carrión, Cegarra-Navarro, \& Jimenez-Jimenez, 2012a; Leal-Rodriguez et al. 2014). Thus, the literature widely supports the existence of a direct link between knowledge management and innovation. Moreover, the concept of learning appears prominently in the frameworks intended to theorize about the composition and running of innovation systems (Grønning \& Fosstenløkken, 2015).

However, knowledge has limitations in terms of its currency. Rampersad (2003) asserts that knowledge becomes obsolete rapidly and both individuals and organizations should adopt and foster an attitude of continuous learning. Firms obtain better performance if its members are able to learn and apply knowledge faster than competitors. In line with Casillas, Acedo, and Barbero (2010, p.163), "learning is the process of acquisition, integration and interpretation of new knowledge with the objective of a later use." In a scenario characterized by volatility, turbulence and continuous change, knowledge quickly becomes outdated (Hedberg, 1981). This rapid obsolescence forces firms to renew their knowledge regularly. This knowledge renewal is unlearning and one of the core weaknesses of many firms is their inability to unlearn. Cepeda-Carrión, CegarraNavarro, and Leal-Millán (2012b, p. 1552) argue that, "the replacement of old knowledge could be essential for organizations that wish to create new products or services that require new points of view and ideas”.

OL is itself a dynamic process in which moments of knowledge forgetting and leaving behind old logics, behaviors, and routines lead to moments of new knowledge acquisition (Hedberg, 1981). Thus, De Holan and Phillips (2004) argue that firms must leave aside certain knowledge, practices, behaviors and routines before they are able to acquire new knowledge. Hence, OU is understood as a dynamic process through which organizations are able to identify obsolete knowledge and routines and then proceed to delete them as a prerequisite for new knowledge absorption. In this line, McGill and Slocum (1993, p.67) state that "the first step to learning is to challenge these ways of thinking that worked so well in the past”.

Bearing in mind together these perspectives and prior findings, we understand OL as a dynamic cycle which requires the existence of a preliminary knowledge base in order to absorb new knowledge (Cohen \& Levinthal, 1990). Furthermore, OU or the abandonment of knowledge that no longer fits the firm's strategy is critical if the organization aims to succeed as an innovative organization. Therefore, we hypothesize: H3: organizational unlearning is positively linked to firm innovativeness. 
Figure 2. Research model and hypotheses

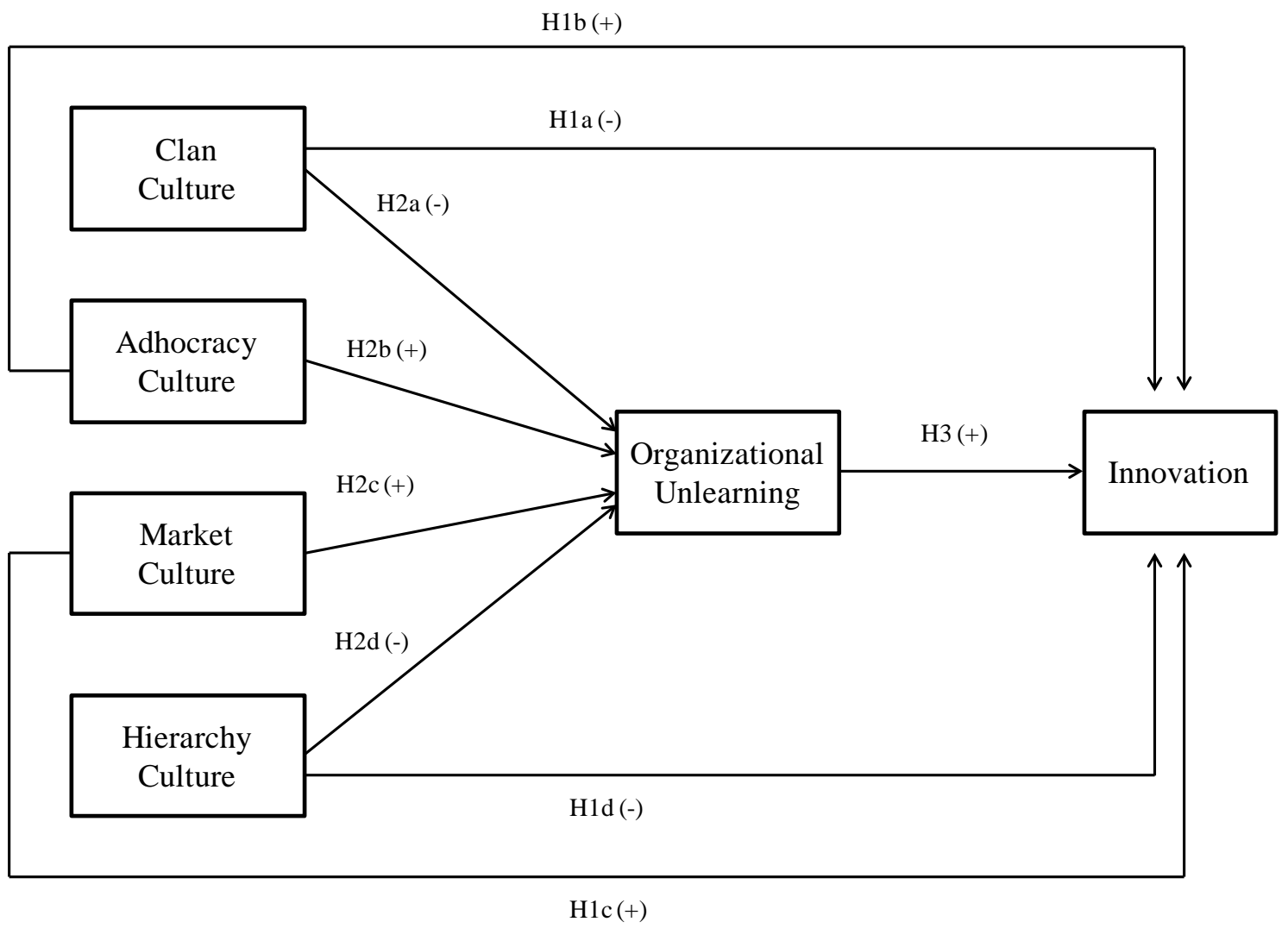

\section{Method.}

\subsection{Data collection and sample}

Data for this research comes from a survey conducted during the period SeptemberNovember 2013. The population includes Spanish firms belonging to the automotive components manufacturing sector. The sample was drawn from a list obtained from Sernauto, the Spanish Association of manufacturers of equipment and components for the automotive industry. From this sector's 906 companies, 418 fulfilled the selection criteria adopted (i.e., being knowledge-intensive companies that pursue innovation). After two mailing efforts, the outcome was 145 usable surveys (i.e., a 34.7\% response rate). The respondents were senior executives of the sample firms. Table 1 presents a series of demographic data with regard to the sample.

Table 1. Demographic data

\begin{tabular}{cccc}
\hline Managerial level & CEO & $\begin{array}{c}\text { Top } \\
\text { Management }\end{array}$ & $\begin{array}{c}\text { Middle } \\
\text { Management }\end{array}$ \\
\hline & 110 & 32 & 3 \\
& $76 \%$ & $22 \%$ & $2 \%$ \\
\hline Sector of activity & Industry & Service & Commercial \\
\hline & 118 & 18 & 9 \\
& $81 \%$ & $12 \%$ & $6 \%$
\end{tabular}




\begin{tabular}{cccc}
\hline Firm size & Small & Medium & Large \\
\hline & 18 & 72 & 55 \\
& $12 \%$ & $50 \%$ & $38 \%$ \\
\hline Firm age & $1-15$ years & $16-30$ years & over 30 years \\
\hline & 12 & 57 & 76 \\
& $8 \%$ & $39 \%$ & $52 \%$ \\
\hline
\end{tabular}

\subsection{Measures}

The survey design was based upon the literature review contained within Section 2. The questionnaire adapted previously validated scales from studies in which the items and responses appear on a seven-point Likert scale, ranging from 1 (completely disagree) to 7 (completely agree). This study measures OC on the basis of the Organizational Culture Assessment Instrument (OCAI) developed by Cameron and Quinn (1999). This scale uses six key dimensions of four items each (i.e., a total of 24 items). In order to assess $\mathrm{OU}$ as an aggregate multidimensional (second order) construct, we used a scale that uses 18 items (five items to measure the examination of lens fitting, six items to measure the consolidation of emergent understanding, and seven items to measure the framework for changing individual habits) proposed by Cegarra and Sánchez (2008). Our study adapted the eight items used by Prajogo and Ahmed (2006) for the innovation construct. Space constraints mean that we cannot include the questionnaire items within this paper though we would be delighted to send the questionnaire to those who may require it.

\subsection{Data analysis}

To test the research model, this study relies on the use of partial least squares (PLS), a variance-based structural equation modeling (SEM) method. PLS is a suitable technique for this study due to the following reasons (Roldán \& Sánchez-Franco, 2012): (1) the sample ( $\mathrm{n}=145)$ is small; (2) the study is focused on the prediction of the dependent variables; (3) the research model involves considerable complexity with regard to the type of relationships in the hypotheses; and (4) this study uses latent variables' scores in the subsequent analysis for predictive purposes. We used the SmartPLS software (Ringle, Wende, \& Will, 2005) for the assessment of both the measurement model and the structural model.

\section{Results.}

Assessing and interpreting PLS models comprises two phases: (1) Assessing the reliability and validity of the measurement model; and (2) Evaluating the significance of the structural model.

\subsection{Measurement model}

Assessing reflective measurement models involves evaluating the model's reliability and validity. Results show that the measurement model meets all common requirements. First, reflective individual items are reliable, as all standardized loadings are greater than 0.707 (Table 2). Consequently, the individual item reliability is 
adequate (Carmines \& Zeller, 1979). Second, all reflective constructs meet the requirement of construct reliability, since their composite reliabilities $(\rho c)$ are greater than 0.7 (Nunnally \& Bernstein, 1994) (Table 2). In addition, these latent variables achieve convergent validity because their average variance extracted (AVE) surpasses the 0.5 level (Fornell \& Larcker, 1981) (Table 2). Finally, all variables meet the requirements of discriminant validity. Confirmation of this validity comes from the comparison of the square root of AVE versus the corresponding latent variable correlations (Table 3). For satisfactory discriminant validity, the diagonal elements should be significantly greater than the off-diagonal elements in the corresponding rows and columns (Roldán \& Sánchez-Franco, 2012).

Table 2. Reflective measurement model

\begin{tabular}{|c|c|c|c|}
\hline CONSTRUCT/indicator & Loading & $\begin{array}{l}\text { Composite } \\
\text { reliability (CR) }\end{array}$ & $\begin{array}{l}\text { Average variance } \\
\text { extracted (AVE) }\end{array}$ \\
\hline ADHOCRACY CULTURE & & 0.955 & 0.781 \\
\hline ac1 & 0.888 & & \\
\hline ac2 & 0.869 & & \\
\hline ac3 & 0.914 & & \\
\hline ac4 & 0.921 & & \\
\hline ac5 & 0.869 & & \\
\hline ac6 & 0.839 & & \\
\hline CLAN CULTURE & & 0.877 & 0.551 \\
\hline cc1 & 0.842 & & \\
\hline cс2 & 0.782 & & \\
\hline cc3 & 0.847 & & \\
\hline сс4 & 0.795 & & \\
\hline cc5 & 0.739 & & \\
\hline cс6 & 0.767 & & \\
\hline MARKET CULTURE & & 0.961 & 0.806 \\
\hline mc1 & 0.903 & & \\
\hline mc2 & 0.926 & & \\
\hline mc3 & 0.898 & & \\
\hline mc4 & 0.831 & & \\
\hline mc5 & 0.894 & & \\
\hline mc6 & 0.929 & & \\
\hline HIERARCHY CULTURE & & 0.926 & 0.676 \\
\hline hc1 & 0.839 & & \\
\hline hc2 & 0.755 & & \\
\hline hc3 & 0.889 & & \\
\hline hc4 & 0.802 & & \\
\hline hc5 & 0.889 & & \\
\hline hc6 & 0.746 & & \\
\hline INNOVATION OUTCOMES & & 0.943 & 0.674 \\
\hline io1 & 0.917 & & \\
\hline
\end{tabular}




\begin{tabular}{ll} 
io2 & 0.906 \\
io3 & 0.881 \\
io4 & 0.889 \\
io5 & 0.914 \\
io6 & 0.897 \\
io7 & 0.887 \\
io8 & 0.877 \\
\hline
\end{tabular}

$\mathrm{p}<0.001$ (based on t(4999), two-tailed test)

The evaluation of formative measurement models at the indicator level comprises the test for potential multicollinearity between items as well as the analysis of weights (Henseler, Ringle, \& Sinkovics, 2009). This study uses IBM-SPSS software to perform a collinearity test. The maximum variance inflation factor (VIF) values for the manifest variables that shape the formative multidimensional construct OU are 4.841, 2.327, and 4.829, respectively, well within the acceptable threshold of 5 (Hair, Ringle, \& Sarstedt, 2011) (Table 3). In this study, weights provide information about how each formative dimension contributes to the OU construct. Hence, weights actually yield a ranking of these dimensions according to their contribution (Henseler et al., 2009). Table 4 reveals that the examination of lens fitting $(0.404)$ and the consolidation of emergent understandings (0.396) represent the most significant dimensions in the composition of the OU construct.

Table 3. Discriminant validity

\begin{tabular}{ccccccc}
\hline & AC & CC & HC & IO & MC & OU \\
\hline AC & $\mathbf{0 . 8 8 4}$ & 0 & 0 & 0 & 0 & 0 \\
CC & -0.298 & $\mathbf{0 . 7 4 2}$ & 0 & 0 & 0 & 0 \\
HC & -0.403 & 0.689 & $\mathbf{0 . 8 2 2}$ & 0 & 0 & 0 \\
I & 0.672 & -0.469 & -0.581 & $\mathbf{0 . 8 2 1}$ & 0 & 0 \\
MC & -0.575 & 0.241 & 0.238 & -0.091 & $\mathbf{0 . 8 9 7}$ & 0 \\
OU & -0.364 & -0.082 & 0.027 & 0.196 & 0.739 & N.A. \\
\hline \multicolumn{5}{r}{ Note: N.A.: not applicable }
\end{tabular}

Table 4. Formative measurement model

\begin{tabular}{lccccc}
\hline \multicolumn{1}{c}{ CONSTRUCT/dimension/indicator } & VIF & Weight & Loading & $\begin{array}{l}\text { Composite } \\
\text { reliability (CR) }\end{array}$ & $\begin{array}{c}\text { Average variance } \\
\text { extracted (AVE) }\end{array}$ \\
\hline $\begin{array}{l}\text { ORGANIZATIONAL UNLEARNING } \\
\text { Examination of lens fitting }\end{array}$ & 4.841 & 0.404 & & N.A. & N.A. \\
oula & & & 0.909 & 0.959 & 0.824
\end{tabular}




\begin{tabular}{|c|c|c|c|c|c|}
\hline ou1b & & & 0.909 & & \\
\hline ou1c & & & 0.902 & & \\
\hline ou1d & & & 0.881 & & \\
\hline ou1e & & & 0.939 & & \\
\hline $\begin{array}{l}\text { Consolidation of emergent } \\
\text { understandings }\end{array}$ & 2.327 & 0.396 & & 0.923 & 0.666 \\
\hline ou2a & & & 0.821 & & \\
\hline ou2b & & & 0.826 & & \\
\hline ou2c & & & 0.776 & & \\
\hline ou2d & & & 0.846 & & \\
\hline ou2e & & & 0.766 & & \\
\hline ou2f & & & 0.857 & & \\
\hline $\begin{array}{l}\text { Framework for changing the individual } \\
\text { habits }\end{array}$ & 4.829 & 0.353 & & 0.973 & 0.839 \\
\hline ou3a & & & 0.937 & & \\
\hline ou3b & & & 0.921 & & \\
\hline ou3c & & & 0.908 & & \\
\hline ou3d & & & 0.904 & & \\
\hline ouße & & & 0.913 & & \\
\hline ou3f & & & 0.910 & & \\
\hline ou3g & & & 0.917 & & \\
\hline
\end{tabular}

N.A.: Not applicable.

$\mathrm{p}<0.001$ (based on $\mathrm{t}(4999)$ ), two-tailed test)

\subsection{Structural model}

Table 5 shows the explained variance (R2) in the endogenous variables and the path coefficients for the model under study. Bootstrapping (5000 samples) provides t-values that allow the evaluation of the statistical significance of the relationships in the research model (Roldán \& Sánchez-Franco, 2012).

Results for the structural model, as revealed by Table 5, provide evidence to support the following hypotheses: H1a; H1c; H2b; H2c; H2d and H3. However, hypotheses H1b; H1d and H2a are not supported.

Table 5. Structural model results

\begin{tabular}{ccccc}
\hline Relationship & Path coefficient & \multicolumn{2}{c}{ Percentile Bootstrap 95\% CI } & Support \\
& & lower & upper & \\
\hline $\mathrm{R}^{2} \mathrm{OU}=0.617$ & & & & \\
$\mathrm{R}^{2} \mathrm{IO}=0.761$ & & & & \\
\hline H1a: Clan $\rightarrow$ OU & $-0.324^{* *}(2.876)$ & -0.516 & -0.070 & Yes \\
H1b: Adhoc $\rightarrow$ OU & $0.042 \mathrm{~ns}(0.391)$ & -0.216 & 0.208 & No \\
H1c: Market $\rightarrow$ OU & $0.819^{* * *}(13.467)$ & 0.671 & 0.913 & Yes \\
H1d: Hier $\rightarrow$ OU & $0.062 \mathrm{~ns}(0.674)$ & -0.147 & 0.213 & No \\
H2a: Clan $\rightarrow \mathrm{IO}$ & $-0.055 \mathrm{~ns}(0.683)$ & -0.235 & 0.081 & No
\end{tabular}




$\begin{array}{ccccc}\text { H2b: Adhoc } \rightarrow \text { IO } & 0.768^{* * *}(11.462) & 0.647 & 0.911 & \text { Yes } \\ \text { H2c: Market } \rightarrow \text { IO } & 0.175^{* *}(2.432) & 0.045 & 0.327 & \text { Yes } \\ \text { H2d: Hier } \rightarrow \text { IO } & -0.281^{* * *}(3.624) & -0.424 & -0.123 & \text { Yes } \\ \text { H3: OU } \rightarrow \text { IO } & 0.349^{* * *}(4.981) & 0.202 & 0.480 & \text { Yes }\end{array}$

Notes: $t$ values in parentheses $* * * \mathrm{p}<0.001$; ** $\mathrm{p}<0.01$; * $\mathrm{p}<0.05$; ns: not significant; based on $\mathrm{t}(4999)$, one-tailed test. $\mathrm{t}(0.05,4999)=1.645 ; \mathrm{t}(0.01,4999)=2.327 ; \mathrm{t}(0.001,4999)=3.092$

\section{Discussion and conclusions.}

Our results reveal that adhocracy is the OC which best fits firm innovativeness. However, its link with OU is not significant. On the other hand, a hierarchy culture acts as a barrier to innovation while its link with OU remains not significant. Interestingly, the two hybrid cultures have different impacts over the considered phenomenon. Firstly, market culture has a positive impact on OU and innovation. Secondly, clan culture exerts a negative effect on OU while its link with innovation is not significant. Finally, we find evidence to support the direct positive relationship between OU on firm innovativeness.

Therefore, firms that foster creativity and struggle to maintain an innovative approach are more likely to identify and attract interesting opportunities that might lead to beneficial outcomes. An innovative approach lets organizations deal better with the turbulence and dynamism of their environment and therefore enables them to achieve and sustain long-term competitive advantages. Furthermore, the embracing of an innovative culture as a proactive strategy signals a response to changes within the sector, technological advancements, or the anticipation of customers' new needs and demands, with the end purpose of differentiating the firm from its competitors, hence improving its business performance (Jansen, Van den Bosch, \& Volberda, 2006).

Results obtained by applying PLS-SEM, a structural equation modeling technique, reveal that adhocracy is the OC which best fits firm innovativeness. However its link with OU is not significant. On the other hand, hierarchy culture acts as a barrier to innovation, while its link with OU remains not significant. Moreover, the two hybrid cultures have different impacts over the considered phenomenon. Firstly, market culture has a positive impact on OU and innovation. Secondly, clan culture exerts a negative effect on OU, while its link with innovation is not significant. Finally, we find evidence to support the direct positive relationship between OU on firm innovativeness.

The managerial and practical implications seem clear. In this vein, it should be stressed the importance of proactively embracing an OU strategy, which may in turn enable firms to effectively anticipate and react to market changes and trends, technological advancements, or the anticipation of customers' needs and demands, with the ultimate purpose of differentiating the firm from its competitors, and hence, improving its innovativeness and organizational performance. Therefore, the adoption of an OC that stresses and facilitates unlearning and innovation should be widely promoted among these firms.

However, our study is not without some limitations. For instance, it only considers firms belonging to a particular sector (i.e. the automotive components manufacturing sector) and within a particular geographical context (Spain). Therefore, researchers 
must be cautious while generalizing these results to different contexts. Secondly, although we provide evidence of causality, causality itself has not been proven. Accordingly to Fornell (1982), causal relationships between variables cannot be proven, as they are always assumed by the researcher. Thirdly, this research relies on individual perceptions and we only used a single method to elicit these perceptions. On the other hand, concerning some further research areas to develop, it might be interesting to assess in depth what are the main drivers and enablers of an unlearning-oriented organizational culture. In this vein, a case study might be valuable, as it may offer us qualitative data and helpful insights to validate our research model.

\section{References.}

Akgün, A. E., Lynn, G. S. \& Reilly, R. (2002). Multi-dimensionality of learning in new product development teams. European Journal of Innovation Management. 5(2), 57-72.

Becker, K. (2005). Individual organizational unlearning: directions and future research. International Journal of Organisation Behaviour, 9(7), 659-670.

Becker, K. (2008). Unlearning as a driver of sustainable change and innovation: three Australian case studies. International Journal of Technology Management, 42(1/2), 89106.

Bennis, W. G. (1966). Changing Organizations, McGraw Hill, New York.

Boothby, D., Dufour, A., \& Tang, J. (2010). Technology adoption, training and productivity performance. Research Policy, 39(5), 650-661.

Burns, T. \& Stalker, H. (1966). The management of innovation, Tavistock, London.

Büschgens, T., Bausch, A., \& Balkin, D. B. (2013). Organizational Culture and Innovation: A Meta-Analytic Review. Journal of Product Innovation Management, 30( 4), 763-781.

Cameron, K. \& Quinn, R. (1999). Diagnosing and Changing Organizational Culture. Based on the Competing Values Framework, Addison-Wesley, Boston, MA.

Casillas, J.C., Acedo, F. J., \& Barbero, J.L. (2010). Learning, unlearning and internationalisation: Evidence from the pre-export phase. International Journal of Information Management, 30, 162-173.

Cegarra-Navarro, J. G.; Eldridge, S. \& Gamo-Sánchez, A. L. (2012). How an unlearning context can help managers overcome the negative effects of counter-knowledge. Journal of Management \& Organization, 18(2), 231-246.

Cegarra, J.G. \& Sanchez, M. (2008). Linking the individual forgetting context with customer capital from a seller's perspective. Journal of the Operational Research Society, 59(12), 1614-1623.

Cepeda-Carrión, G., Cegarra-Navarro, J. G., \& Leal-Millán, A., (2012b) Finding thehospitalinthe-home units’ innovativeness. Management Decision, 50(9), 1596-1617. 
Cepeda-Carrión,G., Cegarra-Navarro, J. G., \& Jimenez-Jimenez, D., (2012a). The Effect of Absorptive Capacity on Innovativeness: Context and Information Systems Capability as Catalysts. British Journal of Management, 23, 110 -129.

Cohen,W. M., \& Levinthal, D. A. (1990) Absorptive capacity: A new perspective on learning andinnovation. Administrative Science Quarterly, Vol 35, pp 128-154.

Cooper, R. G., Edgett, S. J., \& Kleinschmidt, E. J. (2004). Benchmarking best NPD practices-1. Research-Technology Management, 47(1), 31-43.

Cuthill, I. D. H. (2001). Organizational learning and new product development success. Ann Arbor, MI: ProQuest Information and Learning.

Damanpour,F. (1991). Organizational innovation: a meta-analysis of effects of determinants and moderators. Academy of Management Journal, 34, 555-590.

De Holan, P.M., Phillips, N. \& Lawrence, T.B. (2004). Managing organizational forgetting. MIT Sloan Management Review. 45(2), 45-51.

De Long, D. \& Fahey, L. (2000). Diagnosing cultural barriers to knowledge management. Academy of Management Executive, 14(4), 113-27.

Deshpandé, R., Farley, J. U., \& Webster Jr, F. E. (1993). Corporate culture, customer orientation, and innovativeness in Japanese firms: a quadrad analysis. The journal of Marketing, 23-37.

Fiol, C.M. (1996). Squeezing harder doesn't always work: continuing the search for consistency in innovation research. Academy of Management Review, 21, 1012-1021.

Fornell, C., \& Larcker, D. F. (1981). Evaluating structural equation models with unobservable variables and measurement error. Journal of Marketing Research, 18, 39-50.

García-Morales, V.J.; Llorens-Montes, F.J. and Verdu-Jover, A.J. (2006). Antecedents and consequences of organizational innovation and organizational learning in entrepreneurship. Industrial Management \& Data Systems, 106(1), 21-42.

Grønning T., \& Fosstenløkken, S.M. (2015). The Learning Concept Within Innovation Systems Theorizing: A Narrative Review of Selected Publications on National and Regional Innovation Systems. Journal of the Knowledge Economy, 6, 420-436. DOI 10.1007/s13132-014-0216-5

Hair, J. F., Ringle, C. M., \& Sarstedt, M. (2011). PLS-SEM: indeed a silver bullet. Journal of Marketing Theory and Practice, 19(2), 137-149.

Hedberg, B. (1981). How organizations learn and unlearn. In: P. Nystrom and W.H. Starbuck (Eds.), Handbook of Organizational Design. Vol. 1, London: Cambridge University Press. 
Henseler, J., Ringle, C. M., \& Sinkovics, R. R. (2009). The use of partial least squares path modeling in international marketing. Advances in International Marketing, 20, 277-320.

Hernández-Mogollon, R., Cepeda-Carrión, G., Cegarra-Navarro, J. G., \& Leal-Millán, A. (2010). The role of cultural barriers in the relationship between open-mindedness and organizational innovation. Journal of Organizational Change Management, 23(4), 360376.

Jansen, J. J., Van den Bosch, F. A., \& Volberda, H. W. (2006). Exploratory innovation, exploitative innovation, and performance: Effects of organizational antecedents and environmental moderator. Management Science, 52, 1161-1174.

Jaskyte, K. (2004). Transformational leadership, organizational culture, and innovativeness in nonprofit organizations. Nonprofit Management and Leadership, 15(2), 153-168.

Keskin, H., Akgün, A. E., Günsel, A., \& İmamoğlu, S. Z. (2005). The Relationships Between Adhocracy and Clan Cultures and Tacit Oriented KM Strategy. Journal of Transnational Management, 10(3), 39-53.

Leal-Rodríguez, A.L., Ariza-Montes, J.A., Roldán, J.L., \& Leal-Millán, A. (2014). Absorptive capacity, innovation and cultural barriers: A conditional mediation model. Journal of Business Research, 67(5), 763-768.

Liao, S. H., Chang, W. J., Hu, D. C., \& Yueh, Y. L. (2012). Relationships among organizational culture, knowledge acquisition, organizational learning, and organizational innovation in Taiwan's banking and insurance industries, The International Journal of Human Resource Management, 23(1), 52-70.

McGill, M. E., \& Slocum, J. W. (1993). Unlearning the organization. Organizational Dynamics, 22(2), 67-79.

McLaughlin, H. M. (2002). The relationship between learning orientation, market orientation and innovation and their effect on organizational performance. Ann Arbor, MI: ProQuest information and learning.

Nunnally, J. C., \& Bernstein, I. H. (1994). Psychometric theory, third ed. McGraw-Hill,

Pierce J. L., \& Delbecq, A.L. (1977). Organization Structure, Individual Attitudes and Innovation. Academy of Management Review, 2(1), 27-37.

Prajogo, D. I., \& Ahmed, P. K. (2006). Relationships between innovation stimulus, Innovation capacity, and innovation performance. R\&D Management, 36(5), 499-515.

Rampersad, H.K. (2003) Total Performance Scorecard; Redefining Management to Achieve Performance with Integrity. Butterworth-Heinemann Business Books, Elsevier Science, Massachusetts.

Ringle, C. M., Wende, S., and Will, A. (2005) SmartPLS 2.0 (M3) beta. Hamburg. 
Roldán, J. L., \& Sánchez-Franco, M. J. (2012). Variance-based structural equation modelling: guidelines for using partial least squares in information systems research. In: M. Mora, et al. (Eds.), Research methodologies, innovations and philosophies in software systems engineering and information systems. IGI Global, Hershey, PA, 193-221.

Santos-Vijande, L., \& Álvarez-González, L. I. (2007). TQM and firms performance: An EFQM excellence model research based survey. International Journal of Business Science and Applied Management, 2(2), 21-41.

Sanz-Valle, R., Naranjo-Valencia, J. C.,Jiménez-Jiménez, D., \& Perez-Caballero, L. (2011). Linking organizational learning with technical innovation and organizational culture. Journal of Knowledge Management, 15(6), 997 - 1015.

Seddighi, H. (2015). A Model of a Firm's Innovation and Growth in a Knowledge-Based Economy. Journal of the Knowledge Economy, 6, 215-227 DOI 10.1007/s13132-0120136-1.

Senge, P.M. (1990). The Leader's New Work: Building Learning Organizations. Sloan Management Review, 32, Fall, 7-23.

Tellis, G. J., Prabhu, J. C. \& Chandy, R. K. (2009). Radical Innovation Across Nations: The Preeminence of Corporate Culture. Journal of Marketing, 73, 3-23.

Zammuto, R.F., Gifford, B., Goodman, E.A., 2000. Managerial ideologies: organizational culture, and the outcomes of innovation: a competing values perspective. In: Ashkanasy, N., Wilderon, C., Peterson, M. (Eds.), Organizational Culture and Climate. Sage, Thousand Oaks, CA, pp. 261-278.

\section{A. Organizational Culture (OCAI) (Cameron and Quinn, 1999).}

1. My organization is characterized for being...

- A very personal place, almost an extension of family

- A very dynamic and entrepreneurial entity. People are willing to bet on their ideas and take risks

- A very results-oriented entity. People are very competitive and achievementoriented

- A very hierarchical formalized and structured entity. Any activity is provided with previously established standards and procedures

2. Leadership in my organization...

- Is generally identified with orientation (mentoring), facilitation and support (nurturing)

- Is characterized by fostering entrepreneurship, innovation and risks assumption.

- Is characterized by having a practical, aggressive and results-oriented focus

- Is characterized for promoting coordination, organization, the good functioning (operation) and efficiency 
3. The management of the employees in my organization...

- Is characterized by a management style based in teamwork, consensus and participation

- Is characterized by promoting individual initiative, risk-taking, innovation, and uniqueness

- Is characterized by promoting a competitive spirit, high demands and a clear orientation towards achievement

- Is characterized by employment security, compliance, predictability and stability in relations

4. The values shared by the staff in my organization are...

- Mutual loyalty and trust. Great importance is given to the commitment to the Organization

- The commitment to innovation, development and continuous change

- The emphasis on achievement and the consecution of goals or objectives

- Respect for and compliance with standards and formal policies to maintain the good functioning of the firm

5. The strategic priorities in my organization are...

- The development of the person, trust, honesty and participation

- The acquisition of new resources and the creation of new challenges. Originality and the search for opportunities are appreciated

- The actions and competitive achievements. To gain market share is considered to be something predominant

- Permanence, stability, efficiency, control, and the fluidity of the operations are important

6. Success criteria in my organization are based on...

- The development of the Human Resources, teamwork, the employee commitment and the concern for people

- The development of unique and novelty products or services. We aspire to become leaders in production and innovation

- Gaining market share and displacing the competitors. To become the market leader is the key

- Efficiency. Reliable deliveries, refined programming and low cost represent fundamental aspects

B. Organizational Unlearning (Cegarra and Sánchez, 2008).

1. In my company...

- Employees are able to easily identify problems (new ways of doing things)

- Employees are able to identify mistakes from their colleagues

- Employees are able to listen to the customer (eg: complaints, suggestions...)

- Employees are able to easily share information with the Managers

- Employees try to reflect and learn from their own mistakes 
2. In my company...

- Managers seem to be open to new ideas and ways of doing things

- Managers have tried to start projects

- Managers recognize the value of acquiring, assimilating and applying new information

- Managers adopt the employees' suggestions in the form of new routines and processes

- Managers are willing to work together with the employees of the company and resolve problems together

- Managers are concerned about the fact that the way to respond to unforeseen circumstances will be known by all

3. In my company...

- The existence of new situations have helped individuals to identify their own mistakes

- The existence of new situations have helped individuals to undesirable attitudes

- The existence of new situations have helped individuals to identify behaviors improper for the place

- Individuals recognize the forms of reasoning or to arrive at solutions such as inadequate

- The existence of new situations have helped individuals to change their behaviors

- The existence of new situations have helped individuals to change their attitudes

- The existence of new situations have helped individuals to change their thoughts

C. Innovation Outcomes (Prajogo and Ahmed, 2006).

1. In my company...

- The level of novelty (innovation) of the new products is very high

- We use the latest technological innovations in our new products

- We are very quickly in the development of new products

- We have a large number of new products introduced into the market

- We possess a high technological competitiveness in everything we do (greater than all our competitors)

- We are very quickly in the adoption of the latest technological innovations in our processes

- Actuality and novelty of the technology used in our processes are high

- We possess a high rate of change and renewal in our processes, procedures and techniques 